\title{
CLIMATE CHANGE IMPACT ON PLANT PATHOGENS AND PLANT DISEASES
}

\section{What are the possible effects of climate change on plant diseases? May it affect the use of chemicals in agriculture? In these pages you will find an explanation of the possible effects of climate on the interaction among environment, plant and pathogen, which are the key factors in plant disease development.}

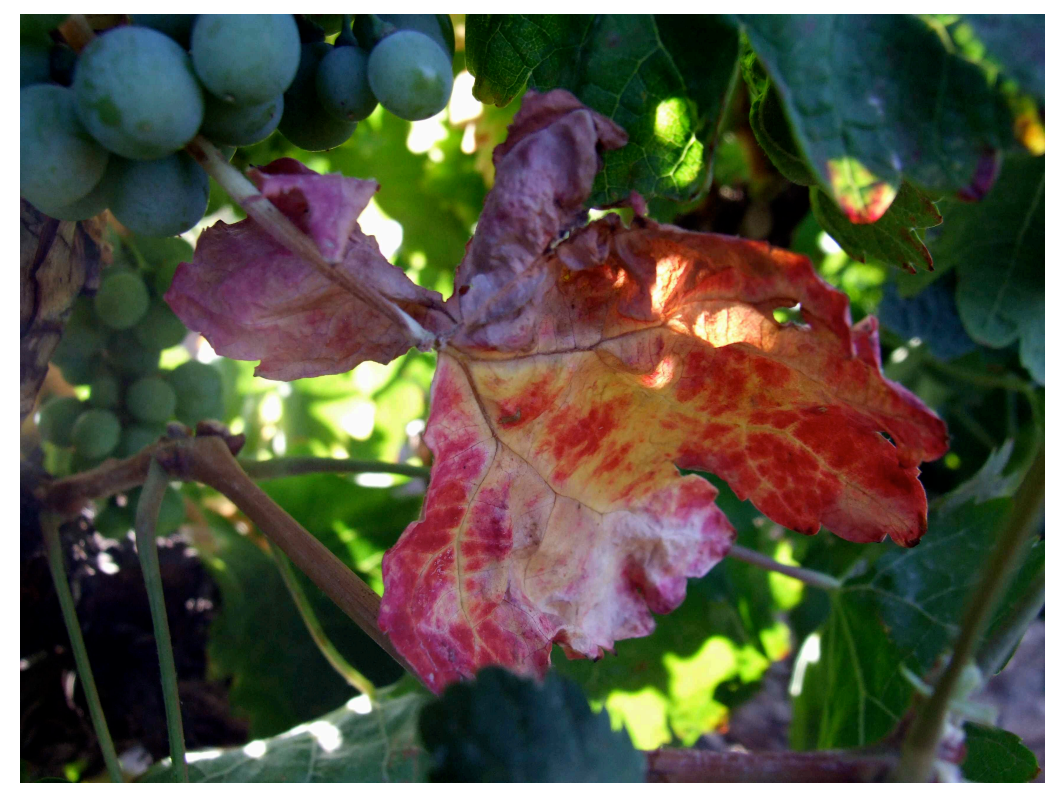

\section{Climate change will affect plant diseases}

A plant disease is the result of interaction between a susceptible host plant, a virulent pathogen(s) and the environment (see the "triangle of the deseases" in the next page). Changes in environmental conditions are strongly associated with differences in the level of losses caused by a disease because the environment significantly (directly or indirectly) influences plants, pathogens and their antagonists. The changes associated with global warming (i.e., increased temperatures, changes in the quantity and pattern of precipitation, increased $\mathrm{CO}_{2}$ and ozone levels, drought, etc.) thus, may affect the incidence and severity of plant disease and influence the further co-evolution of plants and their pathogens (Chakraborty, 2005; Burdon et al., 2006; Garrett et al., 2006; Crowl et al., 2008; Eastburn et al., 2011).

There are already some examples of the effect of past climate changes in some pathosystems.

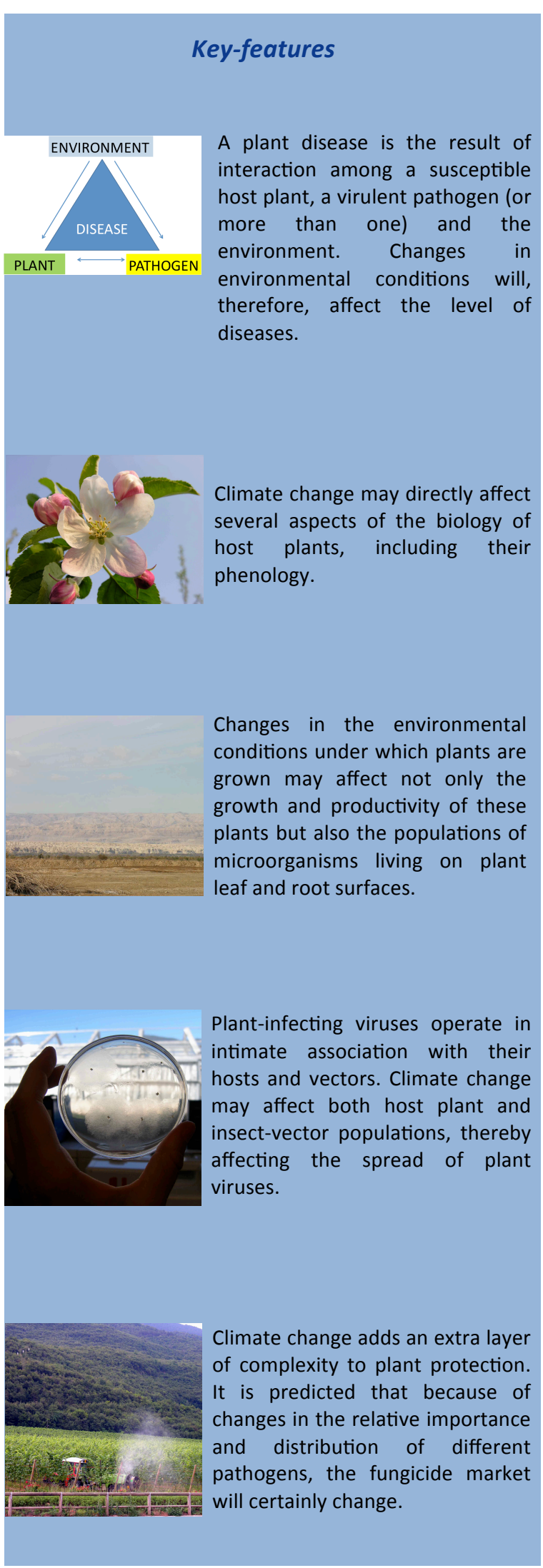




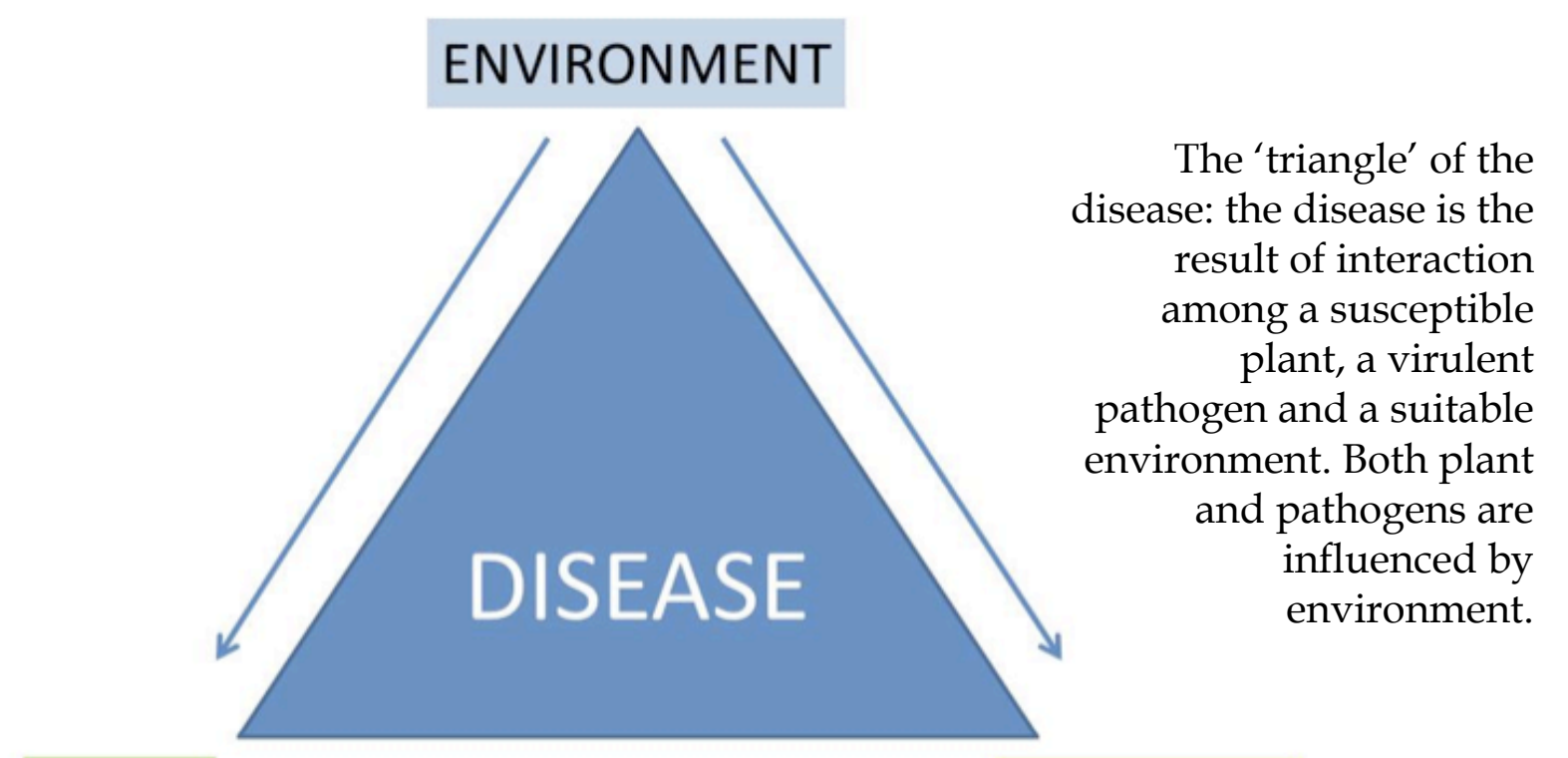

PATHOGEN

The increased mean winter temperatures, the shift in precipitation from summer to winter and the tendency toward heavier rain, which have been noted in central Europe, favor infection by several Phytophthora species and thus increased incidence of root rot in forest trees. For example, in the southern United Kingdom, recent climatic changes have affected the geographical range and severity of phoma stem canker (Leptosphaeria maculans) of oilseed rape (Brassica napus). In particular, an earlier start of the outbreaks and increase severity of the disease was noticed and these changes have been related to increases in temperature, especially during the winter.

\section{Leptosphaeria maculans}

This pathogen causes phoma stem canker (blackleg) on oilseed rape. This disease is of major economic importance in the main oilseed rape growing areas of Australia, Canada and Europe.

Usually it does not totally destruct the crops; yield losses at harvest are usually less than $10 \%$, although they can reach $30-50 \%$.

\section{Phytophtora spp.}

The genus Phytophthora comprises over 60 species, which are plant pathogens of considerable economic importance in agriculture and forestry.

Some species can cause serious forest decline. Affected trees display yellowing of leaves and finally crown dieback, and clear disorders in their root.

In general, forest root and crown rot caused by these species are impossible to control with fungicides; therefore only preventing their dissemination is a reliable control measure.

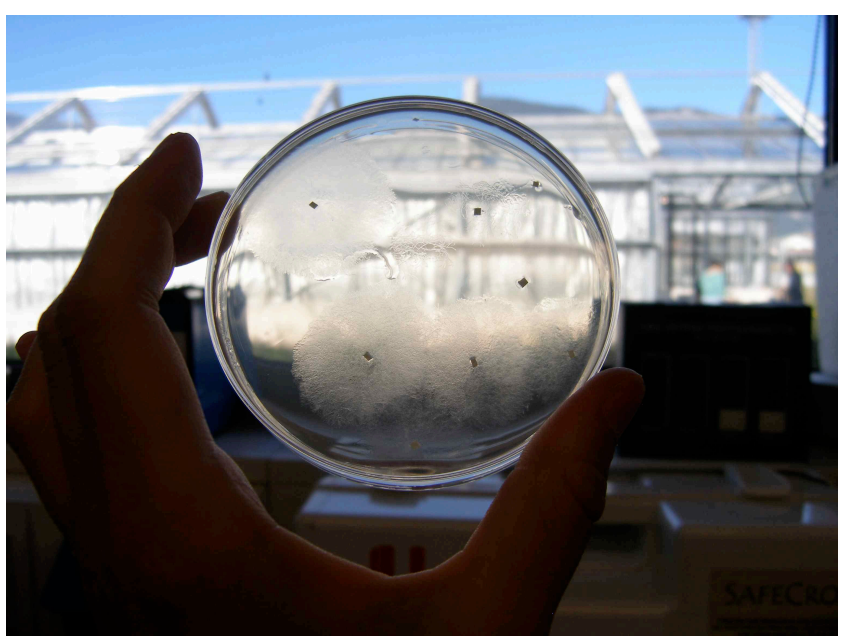

Growth of a plant pathogenic fungus on an artificial culture medium. 


\section{Direct effects of climate change on pathogens}

Several aspects of the biology of a pathogen can be directly influenced by environmental factors. Prolonged periods of environmental conditions (temperature, precipitation and relative humidity $[\mathrm{RH}])$ that are close to the optimal for the development of the pathogen lead to more severe epidemics. Thus, as temperatures increase, many pathogens will spread into new geographic areas, where they will come into contact with new potential hosts. Pathogen survival in the absence of a host (e.g., over-wintering and oversummering) can also be affected by temperature and $\mathrm{RH}$.

The strongest consequences of global warming are expected to be observed in the tropics, because tropical species have a narrow temperature growth range and are, therefore, relatively sensitive to changes in temperature. These species are also currently living very close to their optimal temperature conditions (Ghini et al., 2011a). Pathogens in higher latitudes usually live in climates cooler than their physiological optima; therefore, warming is expected to enhance their fitness and the risk of epidemics of the diseases with which they are associated. Epidemics involving polycyclic pathogens are strongly influenced by the number of generations of the pathogen within a particular time period. Temperature and moisture govern the rate of reproduction of many pathogens (Caffarra et al., 2012).

The longer growing seasons that will result from global warming will extend the amount of time available for pathogen reproduction and dissemination.

Climate change may influence the sexual reproduction of pathogens thereby increasing the evolutionary potential of individual populations.

Environmental factors that cause or accelerate tissue death, such as high temperatures or ozone levels, may favor infection by necrotrophic pathogens.

Pathosystem

A pathosystem is defined by the phenomenon of parasitism. In case of a plant, the host species is the plant and the parasite is any species, which may inhabit the plant obtaining nutrients from it. The parasite may thus be an insect, mite, nematode, parasitic Angiosperm, fungus, bacterium, phytoplasma, virus or viroid.

\section{Biotrophic and necrotrophic pathogens}

Biotrophic pathogens derive their nutrition from living cells and have deep and prolonged physiological interactions with their hosts. Necrotrophic pathogens obtain nutrients from dead tissues and are affected only limitedly by the active metabolism of host plant cells.

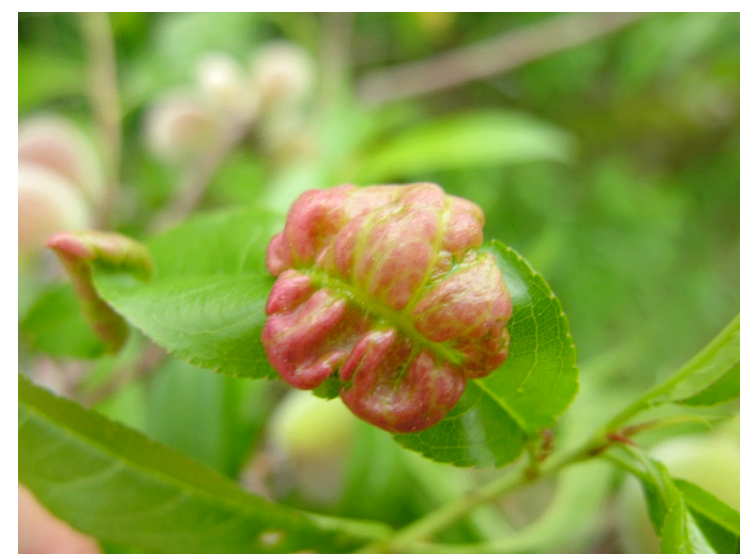

Disease symptom in a leaf caused by Taphina deformans, a biotrophic pathogen of peach.

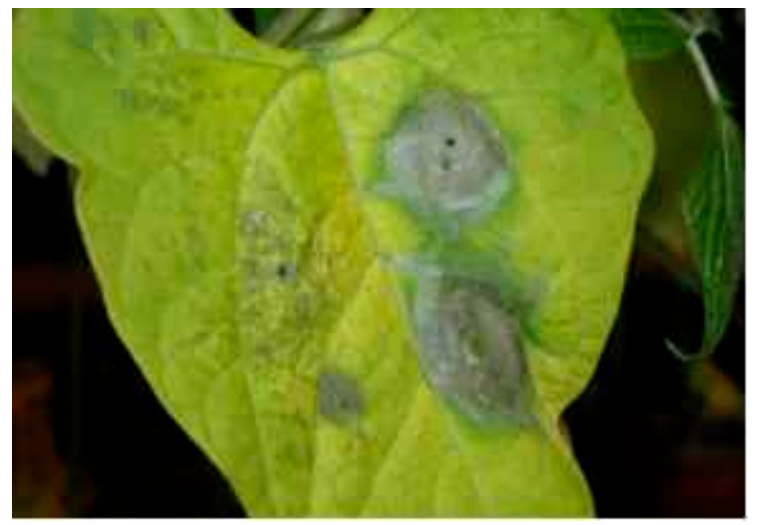

Symptoms on bean leaf caused by the necrotrophic pathogen Botrytis cinerea. 


\section{Direct effects of climate change plant-pathogen interactions}

Climate change may directly affect several aspects of the biology of host plants, including their phenology (including senescence), sugar and starch contents, nitrogen and phenolic contents, root and shoot biomass, number and size of leaves, amount and composition of wax on leaves, changes in stomatal densities and conductance and root exudation. Any change in any of these areas may influence infection and colonization by pathogens.
Factors that affect plant growth, such as elevated levels of $\mathrm{CO}_{2}$, increased temperature or drought, may cause changes in the physiology of the host species that will deeply alter the colonization of host tissues by biotrophic pathogens. Abiotic stress may induce the activation of general defense pathways in plants, which increase resistance, but also increase the susceptibility of the plant to certain pathogens.

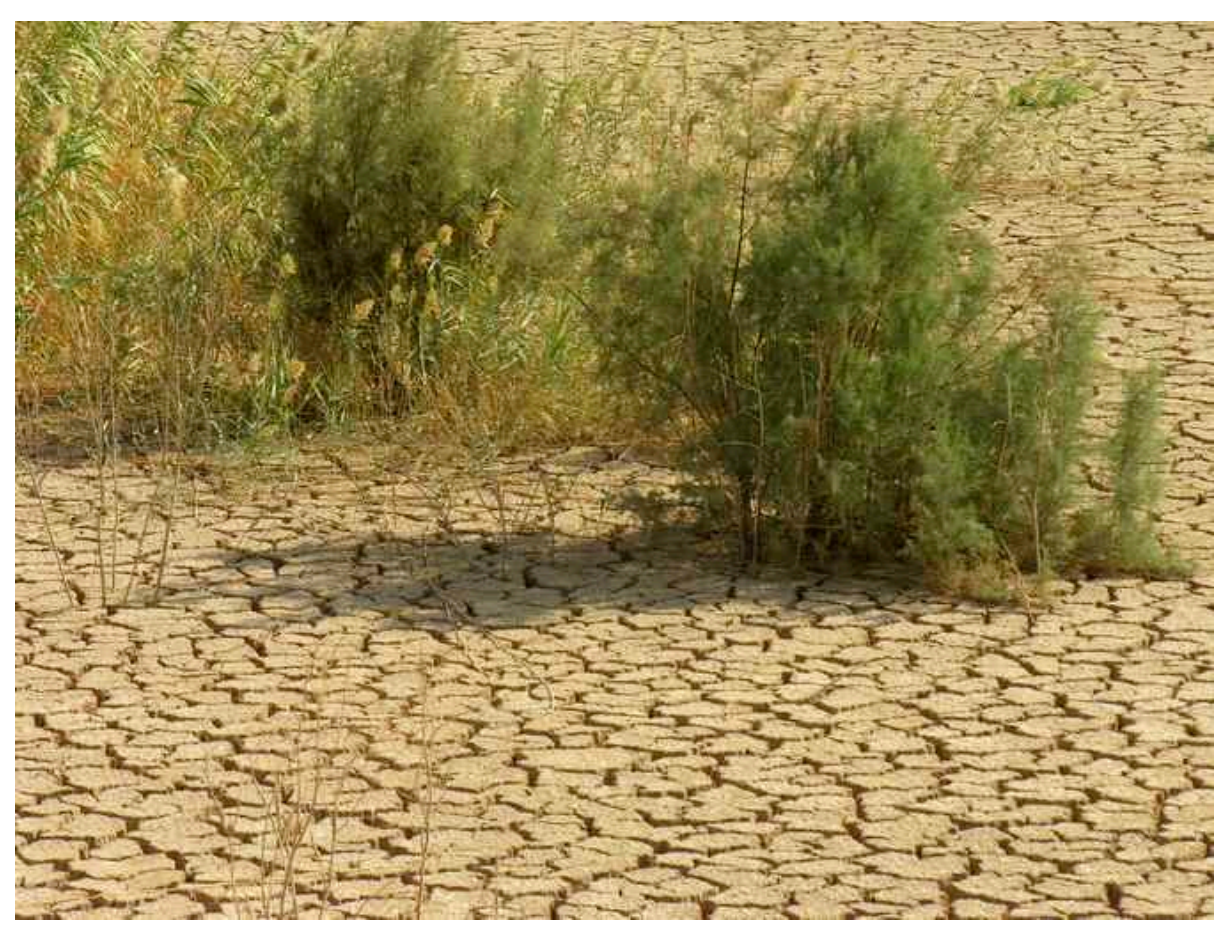

Dried land caused by drought.

Conversely, several diseases are less severe when the availability of moisture is limited. Drought can reduce root growth, which reduces the chance that roots will come into contact with propagules of soilborne pathogens, lowering the incidence of infection. The effect of increased temperature on plants depends on the season. Elevated temperatures reduce plant stress during the winter, but increase the stress on the plant during the summer. In some pathosystems, plants exhibit fewer symptoms when they are subject to drought stress, conversely in some others, plants are more susceptible under drought conditions. Similar to temperature, $\mathrm{CO}_{2}$ and ozone concentrations have increased since the Industrial Revolution.
Moisture and temperature can affect disease development by affecting the susceptibility of the host to infection and/or increasing the level of symptom expression. Water stress causes stomatal closure and reduces photosynthesis. Leaf growth is inhibited and changes in shoot architecture and the root/shoot ratio are commonly observed. In this manner, drought may impair the production of plant defense substances or growth, favoring the progress of the pathogen.
Photosynthesis, leaf area, plant height, total biomass (shoot and root) and crop yield, sugar and starch content, water-use efficiency, growth and yield are increased in the presence of higher levels of $\mathrm{CO}_{2}$. These effects often result in changed plant architecture and the development of larger plant organs. Because many foliar pathogens can take advantage of the more humid microclimate caused by denser plant growth and the higher availability of host tissue, pathogen infection rates of these pathogens usually increase at higher $\mathrm{CO}_{2}$ levels. However, the final effect of increased $\mathrm{CO}_{2}$ concentrations on the disease depends on the interaction between the effects on the pathogen and the effects on the plant under the specific environmental conditions. 
However, the final effect of increased $\mathrm{CO}_{2}$ concentrations on the disease depends on the interaction between the effects on the pathogen and the effects on the plant under the specific environmental conditions.

Elevated ozone concentrations may change the structure and properties of leaf surfaces in ways that may affect the inoculation and infection process.

Ozone enhances senescence processes, may encourage necrosis and seems to promote attacks on plants by necrotrophic fungi.

On the other hand, ozone is an effective abiotic elicitor that influences secondary plant metabolism, as well as the hypersensitive response and systemic acquired resistance.

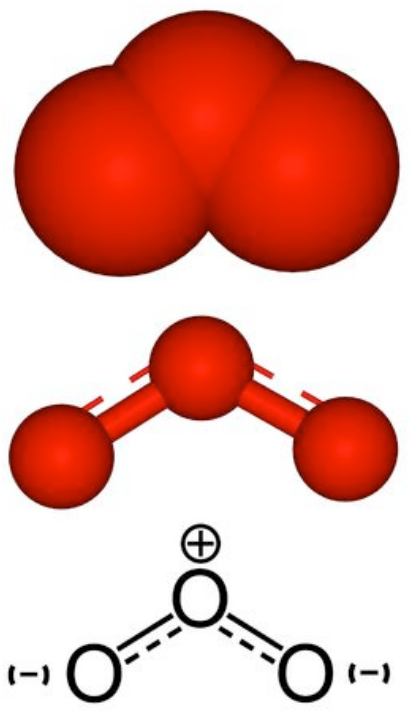

Ozone chemical structure (source: http:/ / commons.wikimedia.org/ wiki/File:Ozone-

\section{Indirect effect of climate change on microbial interactions}

Increased levels of $\mathrm{CO}_{2}$ in the atmosphere are expected to have major consequences on carbon cycling and the functioning of various ecosystems. The increase in fixed carbon may also affect microbial communities in soil and the functioning of the microbial ecosystem. The concentration of $\mathrm{CO}_{2}$ and temperature levels and nitrogen deposition are important factors affecting soil microbial communities (Garret et al., 2006). Therefore, these microbial communities are likely to be affected by climate change.

Short-term and long-term changes in the abiotic conditions under which plants are grown may affect not only the growth and productivity of these plants but also the populations of microorganisms living on plant surfaces.

Changes in microbial populations in the phyllosphere may, in turn, affect plant growth and the plants' ability to withstand aggressive attack by pathogens.

\section{Phyllosphere}

The habitat of the microorganisms living on the leaves or above-ground surface of a plant.

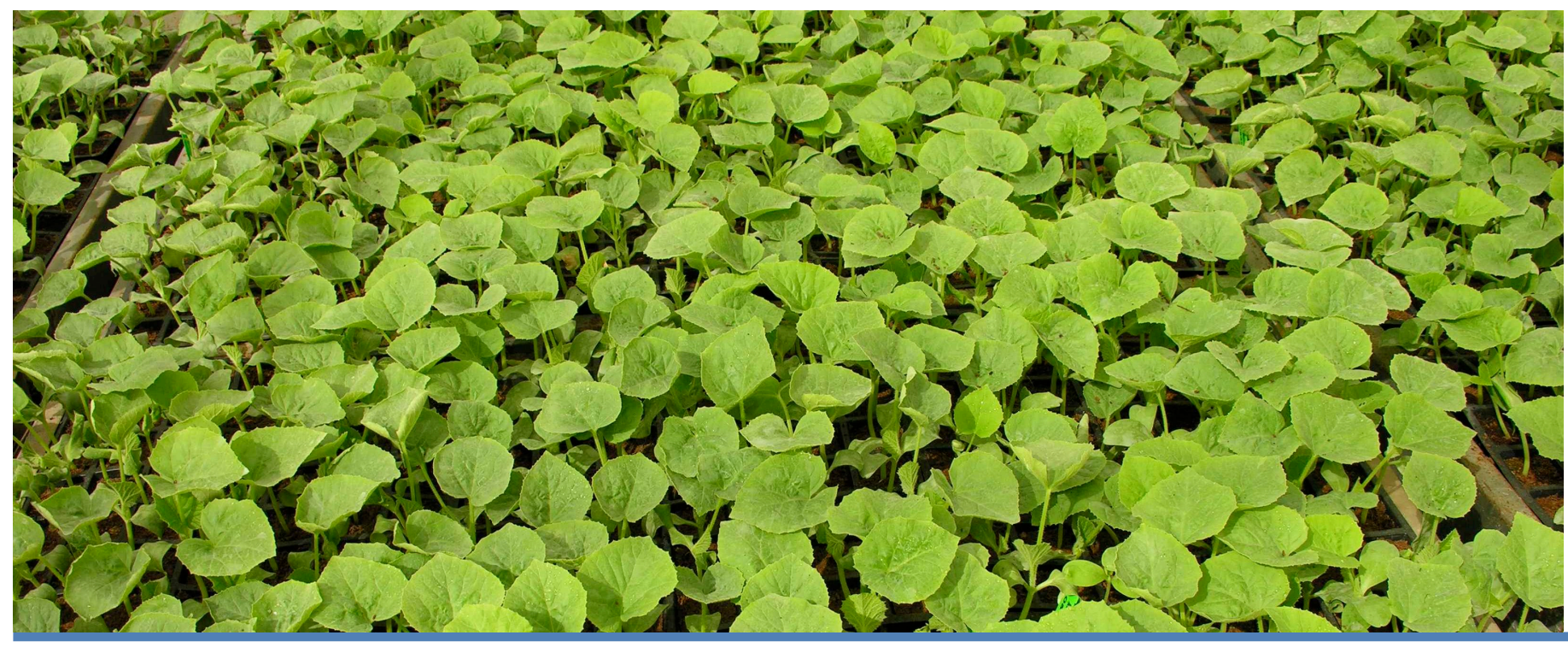




\section{Predictive models in plant pathosystems}

Predictive models have been developed for a few plant-pathogen systems.

Powdery mildew (E. necator) is one of the most important diseases of grapevine. The European grapevine moth (Lobesia botrana) is one of the most noxious vineyard pests in the European and Mediterranean regions. Caffarra et al. (2012) combined detailed phenological models of grapevine with phenological models of grape powdery mildew and the European grapevine moth, applied the models to climate change scenarios for the eastern Italian Alps and considered potential changes in the interactions between these species. Simulations of future powdery mildew epidemics predicted a decrease in disease severity, especially in years in which disease symptoms first appear at a later date and in the presence of significantly increased temperatures. They also suggested that in the warmer, more profitable viticulture areas of the region, increased temperatures might have a detrimental effect on crop yield because of increased asynchrony between the larvaeresistant growth stages of grapevine and European grapevine moth larvae. On the other hand, the increase in pest pressure caused by the increased number of generations might not be as severe as expected on the basis of the pest model only, because of the earlier harvest dates, which would limit the damage caused by late-season generations.

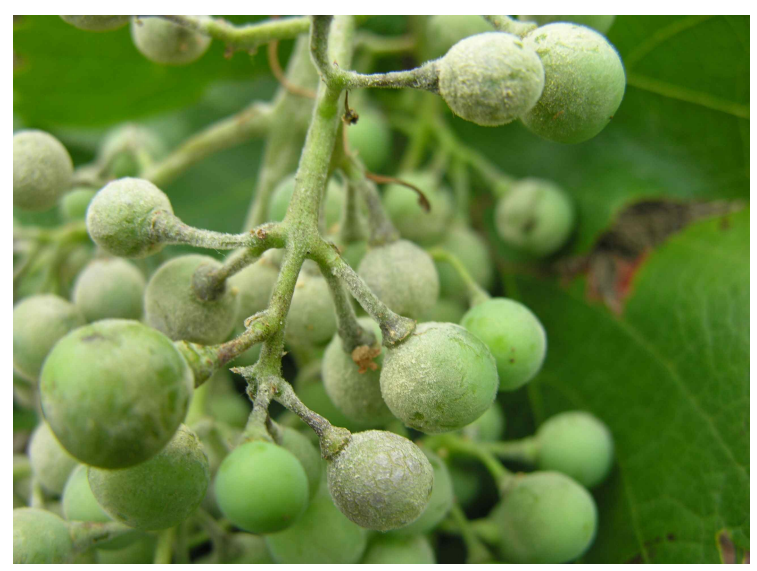

Powdery mildew attack on a grapevine bunch.

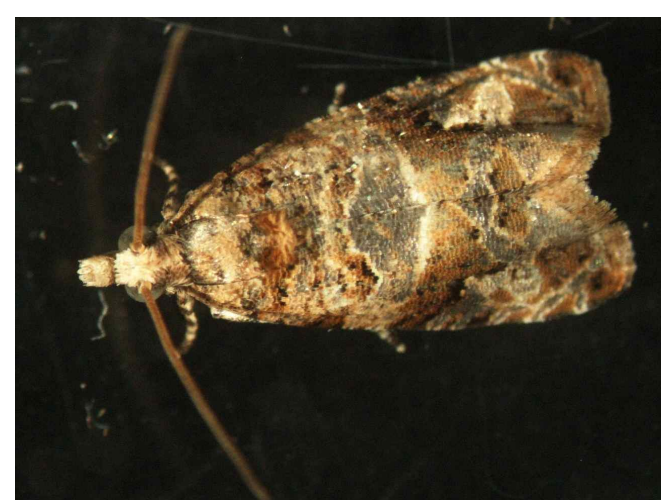

Lobesia botrana (courtesy Gianfranco Anfora).

The obligate parasite $P$. viticola causes downy mildew in grapevine crops around the world. This disease affects both the quantity of harvested grapes and the quality of the wine that can be produced from them. Moisture allows for infection by zoosporangia and dry periods kill the pathogen. (Gessler et al., 2011). The current and future impact of downy mildew on vineyards was studied in Piedmont, Italy. Two global circulation models (GCMs) predicted increased temperatures and decreased precipitation in this region. The simulations obtained by combining the disease model with the two GCM outputs predicted increased levels of disease pressure in each of the three tested future decades following more favorable temperature conditions during the months of May and June. The increased temperatures are predicted to promote the epidemics in ways that will be only partially counteracted by the effects of reduced precipitation, which alone would have diminished disease pressure (Salinari et al., 2006).

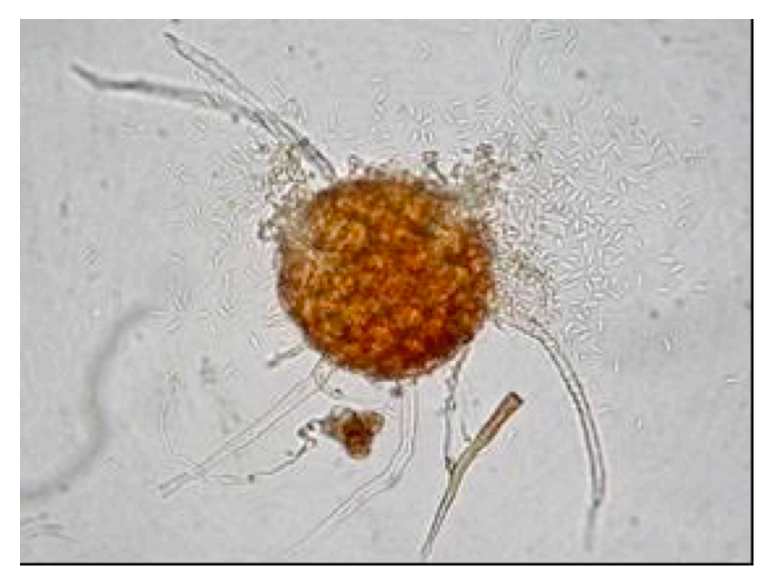

Powdery mildew chasmothecia parasitized by Ampelomyces quisqualis (conidia are visible). 


\section{Effect of climate change on vector-borne diseases}

Plant-infecting viruses operate in intimate association with their hosts and vectors. The risk of vector-borne disease at the local and regional level is limited by the climatic requirements of disease vectors (Malmstrom et al., 2011).

Climate change may affect both host plant and insect-vector populations, thereby affecting the spread of plant viruses (Jones, 2009).

Global warming may influence the primary infection of the host, the spread of the infection within the host and/or the horizontal transmission of the virus to new hosts by the vector.

Climate change may also affect the phenology and physiology of the host, which may affect its susceptibility to the virus and the ability of the virus to infect, as well as the geographic range and densities of alternative hosts/reservoirs. In their turn, the effects on host physiology may affect the attractiveness of the host to vectors and/or viral transmissibility.

Modification of the geographic range of the potential vectors and/or vector phenology, as well as the vector's over-wintering, density, migration and activity can follow.

Virus stability, replication and movement rates, as well as synergism and complementation between viruses can be affected.

Although elevated $\mathrm{CO}_{2}$ levels have been shown to have little direct effect on natural enemies of insect herbivores, they can influence the third trophic level indirectly, by altering the size and composition of populations of prey insects available to predators and/or by disrupting developmental synchrony for parasitoids.

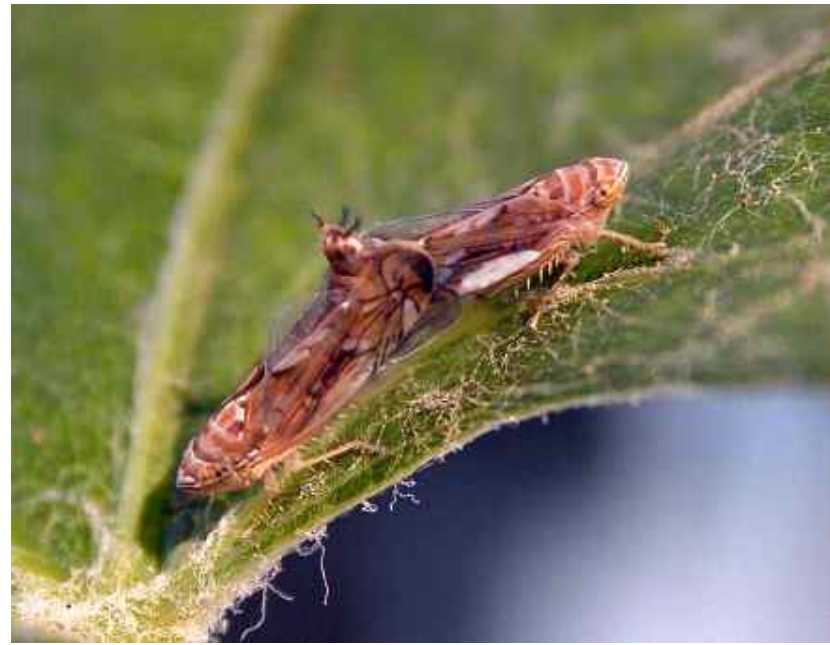

Mating of Scaphoideus titanus, the vector of Flavescence dorée phytoplasma on grapevine (courtesy Valerio Mazzoni).

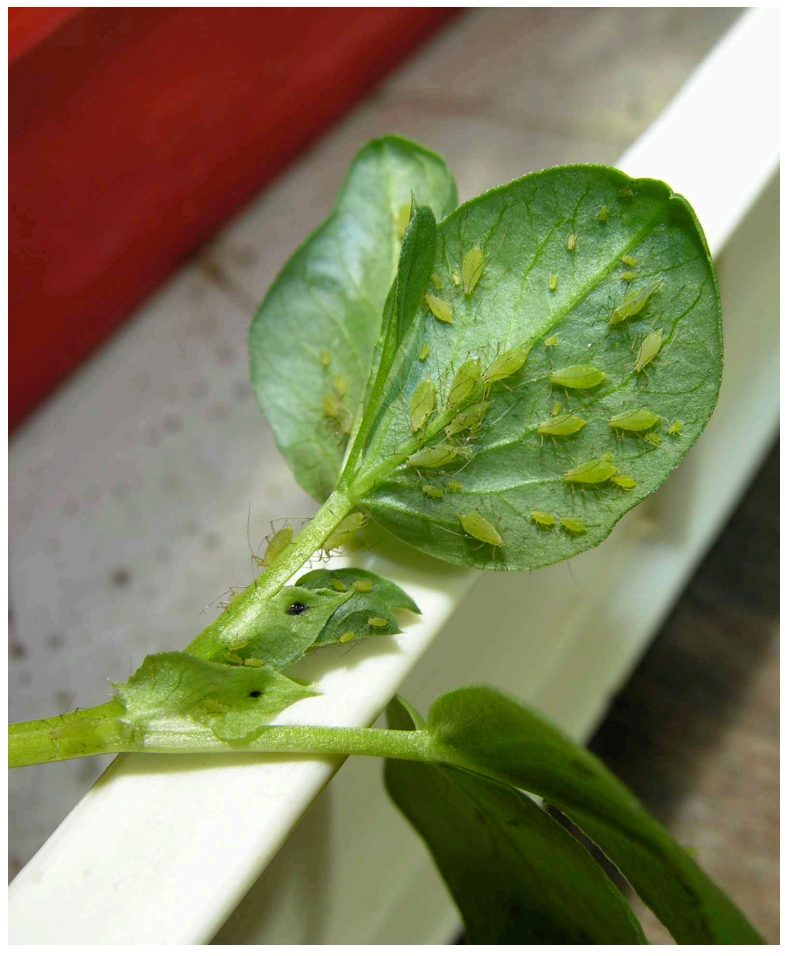

Aphids: these insects are quite often efficient vectors of virus diseases.

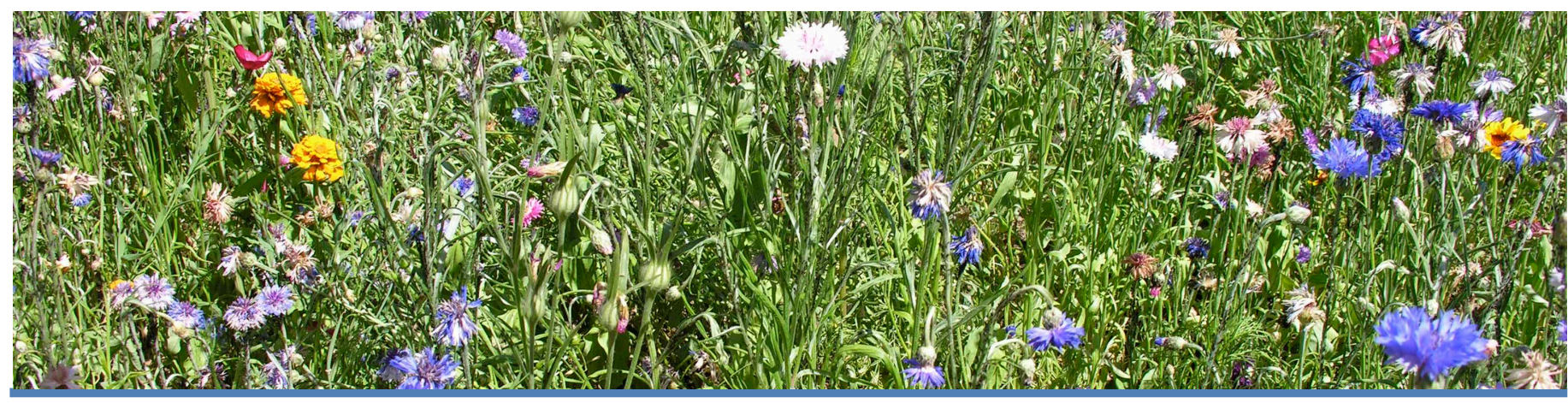




\section{Coping with the effects of climate change on plant diseases}

Disease development is the cumulative effect of various factors that affect the host and pathogen. A slight change in microclimatic conditions can affect the outcome of the plantpathogen interaction. The plant-pathogen relationship can also be affected by microbial populations or control agents. The effects of climate change differ in different plantpathogen systems. Nevertheless, it is clear that such effects will occur and that adaptive measures need to be developed, to allow us to respond to these expected changes.

\section{Climate change adds an extra layer of complexity to plant protection. It is predicted that because of changes in the relative importance and distribution of different pathogens, the fungicide market will certainly change.}

Under worst-case scenarios, several crops may require more fungicide spray treatments or higher application rates, thus increasing costs for farmers, prices for consumers and the likelihood of the development of fungicide resistance (Juroszek and von Tiedemann, 2011). Some agricultural systems may be more flexible than others in the adoption of new cultivars and cultural practices to cope with the increased risk of certain diseases. Annual crops will have an advantage over perennials, as they provide more flexibility when it comes to adopting new cultivars and cultural practices. Potential adaptation strategies must be accompanied by cost-benefit analyses.

Evaluating the efficacy of current physical, chemical and biological control methods under changing climatic conditions and research

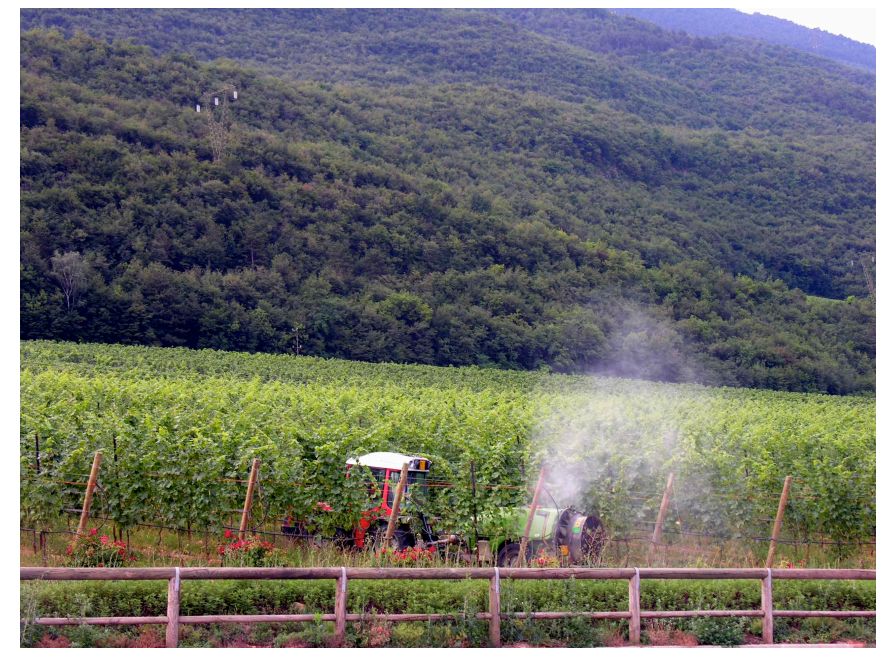

concerning new tools and strategies (including plant breeding) for coping with the predicted changes will be of great strategic importance.

Fungicides may continue to serve as common disease suppression agents, although alternative measures, such as cultural methods and biological control, should be developed.

The persistence of plant protection chemicals in the phyllosphere is highly dependent on weather conditions. Changes in duration, intensity and frequency of precipitation events will affect the efficacy of chemical pesticides and how quickly the active molecules are washed away.

Temperature can directly influence the degradation of chemicals and alter plant physiology and morphology, indirectly affecting the penetration, translocation, persistence and modes of action of many systemic fungicides (Coakley et al., 1999).
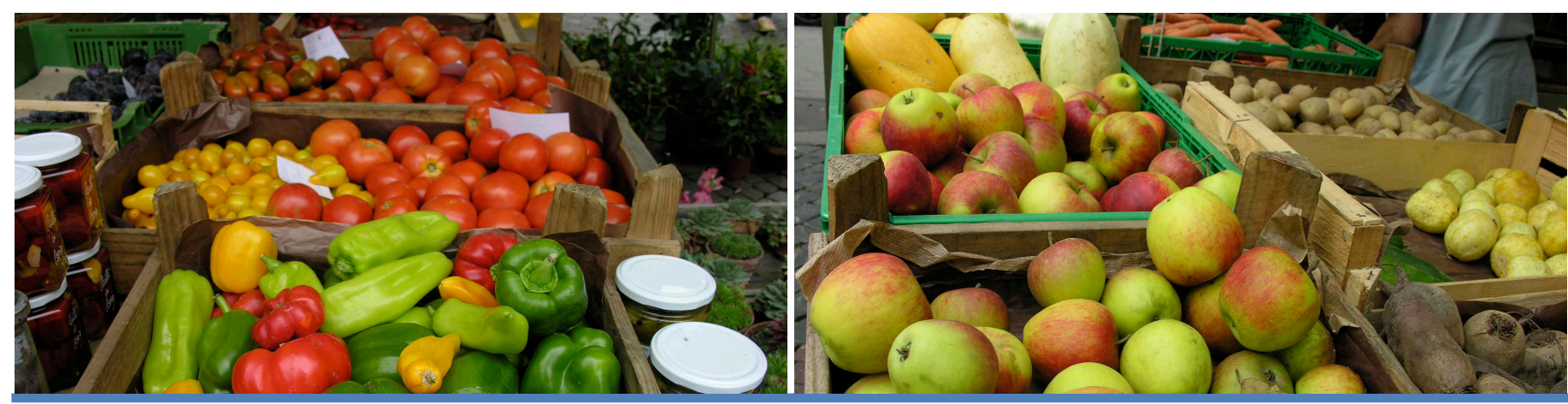
Plant diseases are a major problem not only for food production but also for the quality and safety of important food stuffs. In Europe, mycotoxins and pesticide residues are among the top food safety concerns associated with a changing climate. For example, the concentration of mycotoxin produced by fusarium head blight in grain generally increases with the number of rainy days and days with high $\mathrm{RH}$ but decreases with low and high temperatures. Changes in both temperature conditions and atmospheric composition may influence the severity of outbreaks of fusarium head blight and the production of mycotoxins. The most significant effects on mycotoxin presence generally occur during the production phase, but the entire wheat value chain can be affected (Chakraborty and Newton, 2011).

\section{Metagenomics}

\section{"Metagenomics" describes the collective genetic structure and functional composition of a microbial environmental sample.}

\section{The approach allows the genomic analysis of microorganisms by direct extraction and cloning of DNA from an assemblage of microorganisms, without isolation and culturing the single organisms.}

It has revolutionized the study of complex environments, such as soil, where only a minor part of the residing microorganism can be cultured in artificial media.
Shifts in any of the components of the disease triangle can dramatically affect the magnitude of disease expression in a given pathosystem. Therefore, it is not at all surprising that disease patterns have already changed and will continue to change in response to the effects of climatic changes on pathogens and hosts. The ultimate solution for crop adjustment to climate change is breeding for desired characteristics associated with future needs. Breeding programs for crop plants and forest trees can promote genetic diversity, disease resistance and tolerance of environmental stresses. These breeding goals should, of course, be coupled with traditional breeding goals, such as yield, yield quality and proper shelf-life.

Indigenous microbial communities play an important role in maintaining plant health. There is a need to promote these beneficial communities. Recent technological advances, such as metagenomic analyses will increase our understanding of microbial dynamics in soil and other environments and further advance the establishment of plant pathogensuppressive microbial populations. One adaptation measure that can be imagined is the introduction of beneficial microorganisms (biocontrol agents) to plant surfaces, so that this niche can be occupied in a way that tilts the plant-microorganism interaction in a healthy direction.

Among the beneficial microorganisms that have been examined, there are some that have been found to persist in stressful microclimates. The selection of such microorganisms and the development of preparations for agricultural use may help growers cope with both abiotic and biotic plant stresses.

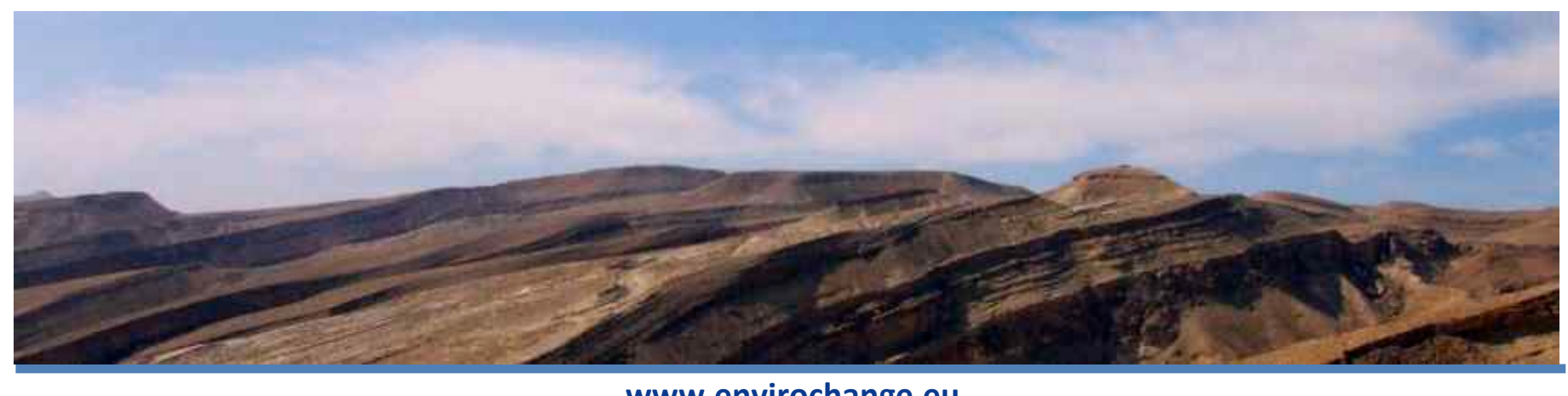




\section{Acknowledgements}

The authors acknowledge the input and assistance in the climate change-plant disease research contributed by Ohad Agra, Hananel Ben Kalifa, Yael Meller Harel, Hellen Angelica Quinonez Gutierrez, Dalia Rav David, Menachem Borenshtein, Ran Shulhani, Benedetta Roatti, Gerardo Puopolo, Amelia Caffarra, Monica Rinaldi and Emanuele Eccel.

\section{To know more}

Burdon, J.J., P.H. Thrall, and A.L. Ericson. 2006. The current and future dynamics of disease in plant communities. Annu. Rev. Phytopathol. 44, 19-39.

Caffarra, A., M. Rinaldi, E. Eccel, V. Rossi, and I. Pertot. 2012. Modeling the impact of climate change on the interaction between grapevine and its pests and pathogens: European grapevine moth and powdery mildew. Agric. Ecosyst. Environ. 148, 89-101.

Chakraborty, S., and A.C. Newton. 2011. Climate change, plant diseases and food security, an overview. Plant Pathol. 60, 2-14.

Coakley, S.M., H. Scherm, and S. Chakraborty. 1999. Climate change and plant disease management. Annu. Rev. Phytopathol. 37, 399-426.

Crowl, T.A., T.O. Crist, R.R. Parmenter, G. Belovsky, and A.E. Lugo. 2008. The spread of invasive species and infectious disease as drivers of ecosystem change. Frontiers Ecol. Environ. 6, 238-246.

Eastburn, D.M., A.J. McElrone, and D.D. Bilgin. 2011. Influence of atmospheric and climatic change on plant-pathogen interactions. Plant Pathol. 60, 54-69.

Garrett, K.A., S.P. Dendy, E.E. Frank, M.N. Rouse, and S.E. Travers. 2006. Climate change effects on plant disease: genomes to ecosystems. Annu. Rev. Phytopathol. 44, 489-509.

Gessler, C., I. Pertot, and M. Perazzolli. 2011. Plasmopara viticola: A review of knowledge on downy mildew of grapevine and effective disease management. Phytopathol. Mediterr. 50, 3-44.

Ghini, R., W. Bettiol, and E. Hamada. 2011a. Diseases in tropical and plantation crops as affected by climate changes: Current knowledge and perspectives. Plant Pathol. 60, 122-132.

Jones, R.A.C. 2009. Plant virus emergence and evolution: Origins, new encounter scenarios, factors driving emergence, effects of changing world conditions, and prospects for control. Virus Res. 141, 113-130.

Juroszek. P., and A. von Tiedemann 2011. Potential strategies and future requirements for plant disease management under a changing climate. Plant Pathol. 60, 100-112.

Malmstrom, C.M., U. Melcher, and N.A. Bosque-Pérezc. 2011. The expanding field of plant virus ecology: Historical foundations, knowledge gaps, and research directions. Virus Res. 159, 84-94.

Salinari, F., S. Giosuè, F.N. Tubiello, A. Retorri, V. Rossi, F. Spanna, C. Rosenzweig, and M.L. Gullino. 2006. Downy mildew (Plasmopara viticola) epidemics on grapevine under climate change. Glob. Change Biol. 12, 1299-1307. 


\section{THE ENVIROCHANGE PROJECT}

The EnviroChange project focuses on global change and sustainable management of agriculture in highly developed mountain environment.

It aims at assessing the short-term biological, environmental and economic impact of climatic change on agriculture at the level of the Trentino region particularly on quality and pest management that are more likely to be influenced by climate change in the short term. The final aim is to preserve and improve the quality of life of habitants, protecting environment and biodiversity for the future generations, as well as to represent a model for sustainable development of mountain areas.

Authors of this essay are: Ilaria Pertot (ilaria.pertot@fmach.it), Fondazione Edmund Mach and

Published by Fondazione Edmund Mach

September 2012

Yigal Elad (elady@volcani.agri.gov.il), The Volcani Center

EnviroChange is coordinated by:

- Fondazione Edmund Mach-Istituto agrario di S. Michele all'Adige (FEM, http://www.fmach.it), Research and Innovation Centre, Italia

Scientific coordinator: Ilaria Pertot, ilaria.pertot@fmach.it

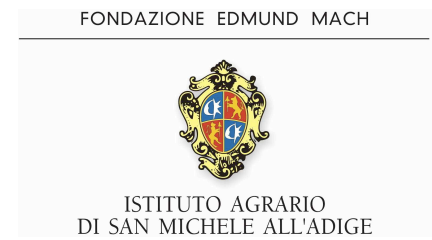

Partners:

- Fondazione Bruno Kessler (FBK, http://cit.fbk.eu/en/home), Italia Scientific partner: Cesare Furlanello, furlan@fbk.eu

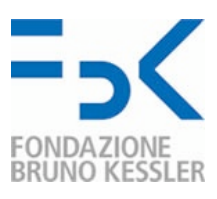

- Agricultural Research Organization (ARO, http://www.agri.gov.il/en/departments/12.aspx), The Volcani Center, Israel Scientific partner: Yigal Elad, elady@volcani.agri.gov.il

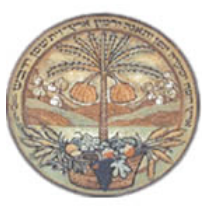

- Swiss Federal Institute of Technology Zurich (ETH, http://www.path.ethz.ch), Institute of plant sciences, Switzerland Scientific partner: Gessler Cesare, cesare.gessler@usys.ethz.ch

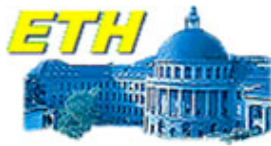

- Università degli studi di Trento, (UNITN, http://portale.unitn.it/deco), Dipartimento di economia, Italy Scientific partner: Roberta Raffaelli, roberta.raffaelli@unitn.it

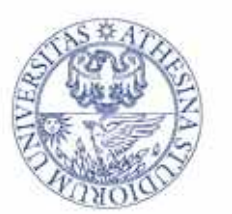

The project is funded by Provincia Autonoma di Trento, Italy 